\title{
1 SHEAR HEATING AND CLUMPED ISOTOPE REORDERING IN CARBONATE FAULTS
}

2 Shalev Siman-Tov ${ }^{\mathrm{a},{ }^{*},}$, Hagit P. Affek ${ }^{\mathrm{a}, \mathrm{b}}$, Alan Matthews ${ }^{\mathrm{a}}$, Einat Aharonov ${ }^{\mathrm{a}}$, Ze'ev Reches $^{\mathrm{c}}$

$3{ }^{a}$ The Fredy \& Nadine Herrmann Institute of Earth Sciences, The Hebrew University of

4 Jerusalem, Edmond J. Safra Campus, Jerusalem 91904, Israel.

$5 \quad{ }^{\mathrm{b}}$ Department of Geology and Geophysics, Yale University, New Haven, CT 06520, USA.

$6 \quad{ }^{c}$ School of Geology and Geophysics, University of Oklahoma, 100 E Boyd St., Norman, OK

7 73019, USA.

ABSTRACT

Natural faults are expected to heat rapidly during seismic slip and to cool quite quickly after

10 the slip event. Here we examine clumped isotope thermometry for its ability to identify short

11 duration elevated temperature events along frictionally heated carbonate faults. Our approach is

12 based on measured $\Delta_{47}$ values that reflect the distribution of oxygen and carbon isotopes in the

13 calcite lattice, measuring the abundance of ${ }^{13} \mathrm{C}-{ }^{18} \mathrm{O}$ bonds, which is affected by temperature. We

14 examine three types of calcite rock samples: (1) crushed limestone grains that were rapidly

15 heated and then cooled in static laboratory experiments, simulating the temperature cycle

16 experienced by fault rock during earthquake slip; (2) limestone samples that were experimentally

17 sheared to simulate earthquake slip events; and (3) samples from Fault Mirrors (FMs) collected

18 from principle slip surfaces of three natural carbonate faults. Extensive FM surfaces are believed

Corresponding author: E-mail address: shalevst@gmail.com (Shalev Siman-Tov).

Abbreviations:

FM - Fault mirror.

PSZ - Principal slip zone

KG - Kfar Giladi

BL - Brown Lueders

DG - Dover gray

(C) 2016. This manuscript version is made available under the Elsevier user license http://www.elsevier.com/open-access/userlicense/1.0/ 
19 to form during earthquake slip. Our experimental results show that $\Delta_{47}$ values decrease rapidly (in

20 the course of seconds) with increasing temperature and shear velocity. On the other hand,

21 carbonate shear zones from natural faults do not show such $\Delta_{47}$ decrease. We suggest that the

$22 \Delta_{47}$ response may be controlled by nano-size grains and highly stressed/strained grain boundaries

23 within the carbonate fault zone that can reduce the activation energy for diffusion, and thus lead

24 to an increased rate of isotopic disordering during shear experiments. In our laboratory

25 experiments the high stress and strain on grain contacts and the presence of nanograins thus

26 allows for rapid disordering so that a change in $\Delta_{47}$ occurs in a very short and relatively low

27 intensity heating events. In natural faults it may also lead to isotopic ordering after the cessation

28 of frictional heating thus erasing the high temperature signature of $\Delta_{47}$.

29

30 Keywords: fault-mirror, shear heating, high-velocity shear, clumped isotope

31 thermometry, calcite, diffusion 


\section{INTRODUCTION}

33 The present study attempts to resolve two problems that are not obviously related to one

34 another: first, we aim to find a method for recognizing past earthquakes that occurred along

35 carbonate faults, possibly using clumped isotope thermometry; second, we aim to understand the

36 mobilization of stable isotopes within the calcite lattice during short heating durations and its

37 effect on clumped isotopes during such events. To address these issues, we conducted both high-

38 velocity shear experiments and static, fast heating experiments, and measured the stable isotopes

39 distribution as function of the experimental conditions. This approach aims to provide a

40 quantitative thermometer for frictional heating, which has critical implications for the seismic

41 behavior of carbonate faults (Boneh et al., 2013; Di Toro et al., 2011).

42 Earthquakes nucleate and propagate along faults (Scholz, 2002). Identifying past seismic

43 events on faults contributes to our understanding of the physics of fault slip, sheds light on

44 paleoseismology, and improves present seismic hazard assessments. The common way to identify

45 seismic slip is by finding clues for past high temperatures experienced by the fault principal slip

46 zone (PSZ). Slip motion on an extremely narrow shear zone (the PSZ) is expected to be

47 accompanied by heat production ("shear heating") due to frictional sliding, and therefore lead to

48 an increase in temperature (McKenzie and Brune, 1972; Rice, 2006). Despite the need to

49 understand thermal history as a recorder of the friction evolution and as a tell-tale signal of past

50 earthquakes, there are very few methods to trace the thermal history in faults post-slip (Rowe and

51 Griffith, 2015). Recent studies reveal possible indicators for temperature increase in sedimentary

52 rocks using thermal maturation of organic molecules (Savage et al., 2014), and in carbonate PSZs

53 by identifying structures related to thermal decomposition (Collettini et al., 2013; Rowe and

54 Griffith, 2015). 
Here, we test clumped isotope thermometry as a geochemical indicator for past heating of slip surfaces of carbonate faults, and hence as an indicator for past earthquake occurrences. Carbonate

57 clumped isotope thermometry utilizes the temperature dependent preference of heavy, rare stable

58 isotopes to bind together. This method analyzes the relative abundance of ${ }^{13} \mathrm{C}-{ }^{18} \mathrm{O}$ bonds in the

59 carbonate lattice, as is measured in $\mathrm{CO}_{2}$ gas that is extracted from the carbonate. The $\Delta_{47}$ values

60 reflect the over-abundance of mass 47 isotopologues with respect to that expected from random

61 distribution of ${ }^{13} \mathrm{C}$ and ${ }^{18} \mathrm{O}$ isotopologues (Affek, 2012; Eiler, 2007; Ghosh et al., 2006; Wang et

62 al., 2004). Equilibrium $\Delta_{47}$ varies inversely with temperature. As such, the $\Delta_{47}$ values reflect the

63 level of order within a carbonate lattice and may be affected by heat induced reorganization of

64 atoms within the lattice.

65 Several studies have examined experimentally the rate of clumped isotopes reordering by

66 heating to high temperatures at time scales of minutes to days (Henkes et al., 2014; Passey and

67 Henkes, 2012; Stolper and Eiler, 2015). These studies show that $\Delta_{47}$ values decrease when calcite

68 is heated, whereas the bulk isotopic composition $\left(\delta^{18} \mathrm{O}\right.$ and $\left.\delta^{13} \mathrm{C}\right)$ remains unchanged. The

69 temperature to which the carbonate is heated determines the reaction rate, which increases with

70 temperature, as well as the equilibrium value of $\Delta_{47}$ that decreases as a function of temperature.

71 As geologically relevant time scales are usually much longer than those of experiments, Passey

72 and Henkes (2012) derived a first order kinetic model for clumped isotope resetting in the

73 carbonate lattice that focuses on reordering rates derived from long term experiments $\left(10^{3}-10^{4}\right.$

74 minutes, up to 44 days). More recently, the models also address the non first order kinetics

75 observed in the early phase of heating experiments, in which reordering is faster (Henkes et al.,

76 2014; Stolper and Eiler, 2015). These models allow for the theoretical calculation of expected $\Delta_{47}$

77 changes during short heating experiments (less than several hundred minutes), and may be 
78 applicable for even shorter heating events, in the order of seconds or less, such as those occurring

79 in fault slip. They suggest two different physical approaches to consider the change in reordering

80 rates with time. Henkes et al. (2014) suggest a model involving a decrease in defect concentration

81 with time due to defect annealing at high temperature. Stolper and Eiler, (2015) suggest a model

82 that considers reordering as an isotope exchange reaction between neighboring carbonates within

83 the lattice, with an early phase of fast loss of ${ }^{13} \mathrm{C}-{ }^{18} \mathrm{O}$ bonds, followed by a phase of slower loss

84 due to parallel recovery of ${ }^{13} \mathrm{C}-{ }^{18} \mathrm{O}$ bonds, that is limited by diffusion of carbonate ions to create

85 the relevant neighbors for such recovery. Here we study experimentally the influence of short-

86 term heating (seconds) on clumped isotope reordering in calcite crystals and discuss it in the

87 context of the Henkes et al. (2014) and Stolper and Eiler, (2015) observations and models. By

88 comparing the experimental data to $\Delta_{47}$ in PSZ samples from natural faults, we consider the

89 possible effects of grain-size reduction, crystal defects, and high stress and strain on $\Delta_{47}$ through

90 reduction of activation energy of diffusion under shear conditions.

91 A main aim of this paper is to analyze $\Delta_{47}$ changes induced by shear heating in faults. We

92 study the region within the fault where shear heating is expected to be most intense. In carbonate

93 faults this region is easily identified as 'fault mirrors' (FMs), which are localized regions, that

94 focus most of the slip and most of the shear heating (Fondriest et al., 2013; Siman-Tov et al.,

95 2015, 2013; Smith et al., 2013). Carbonate fault mirrors consist of $\sim 1 \mu \mathrm{m}$ layer of sintered

96 nanograins and form in the following way: during shear, un-sheared limestone comprising

97 micron size or larger calcite crystals is detached from the bare surfaces of the rock, broken into

98 small fragments, and milled down to nano-size grains (Chester et al., 2005; Reches and Dewers,

99 2005; Siman-Tov et al., 2013; Storti et al., 2003; Wilson et al., 2005). This comminution process

100 also induces a large number of crystal defects that may form a dense array of grain boundaries 
101 and eventually nanograins (Koch, 1997; Siman-Tov et al., 2013). Under extreme heat and stress

102 conditions, as prevail within the principle slip zone of rapidly sliding faults, the nanograins

103 become sintered together into hard, shiny, very smooth surfaces, termed fault mirrors (FMs, see

104 Siman-Tov et al., 2015, 2013; Smith et al., 2013). The critical velocity for FM formation was

105 observed experimentally to be $>0.05 \mathrm{~m} / \mathrm{s}$, when using a load of 1-27 MPa and slip displacement

$106>0.02$ m (Fondriest et al., 2013; Siman-Tov et al., 2015; Smith et al., 2013). Therefore, FMs were

107 suggested as an indicator for seismic slip in relatively shallow-crust carbonate faults.

108 Fault mirrors are expected to be well suited for studying the relations between shear heating

109 and clumped isotope in the shallow-crust $(<1 \mathrm{~km})$. At this depth, the clumped isotopes values of

110 background rock material most likely reflect the temperature during the original carbonate

111 deposition (at Earth surface conditions) with diagenetic modifications at temperatures relevant to

112 the shallow crust. These would be clearly distinguishable from the expected heating signals of

113 fault mirrors.

114 2. Material AND Methods

115 We explore the change in $\Delta_{47}$ by experiments of either static heating or shear heating in which

116 limestone is sheared under variable slip rates. These two sets of experimental samples (described

117 below) are compared to samples collected from natural FMs that constitute the principle slip

118 zones of natural faults that are thought to have experienced earthquakes.

119 2.1. Rock SAMPLES AND GEOLOGICAL SetTINGS

120 The static heating experiments were conducted using powdered limestone from Kfar Giladi

121 (KG) quarry, northern Israel $\left(33^{\circ} 14^{\prime} 29^{\prime \prime} \mathrm{N}, 35^{\circ} 33^{\prime} 49^{\prime \prime} \mathrm{E}\right)$. The quarry is cut by a series of active

122 faults at the margins of the Dead-Sea transform (Nuriel et al., 2012a, 2012b; Siman-Tov et al., 
123 2013; Weinberger et al., 2009). The KG limestones belong to the Eocene Bar-Kokhba Formation,

124 which is a shelf facies comprised mostly of bio-micritic limestone with nummulites (Nuriel et al.,

125 2012b; Weinberger et al., 2009).

126 In the shear experiments we used samples of $\mathrm{KG}$ limestone, as well as slabs of commercially 127 obtained Brown Lueders (BL) and Dover Gray (DG) limestones. The BL is a fine-grained 128 Permian limestone from Lueders, Texas. It is a bio-micritic rock mostly comprised of calcite with

$129 \sim 15 \%$ porosity and is macroscopically homogenous and isotropic (Heard et al., 1972). The DG is

130 a crystalline, low porosity light gray Carboniferous limestone from the Wabaunsee group in 131 Kansas (Moore, 1936).

132 We analyzed three natural fault surfaces: from the KG quarry (Israel; described above), from 133 the Spoleto thrust $\left(42^{\circ} 44^{\prime} 3^{\prime \prime} \mathrm{N}, 12^{\circ} 45^{\prime} 12^{\prime \prime} \mathrm{E}\right)$, and from the Monte Maggio fault $\left(42^{\circ} 45^{\prime} 42^{\prime \prime} \mathrm{N}\right.$, $13412^{\circ} 56^{\prime} 27 " \mathrm{E}$ ) both in the Umbria-Marche Apennines (Italy). FM surfaces in KG quarry were 135 sampled from an oblique strike-slip segment (Siman-Tov et al., 2013). The fault strikes NNE136 SSW and cuts through the Bar-Kokhba Eocene limestone. The estimated total displacement along 137 this segment is 10-100 m, and fault exhumation is estimated as <100 m (Siman-Tov et al., 2015). 138 Spoleto is a thrust fault that was exhumed from $\sim 1.6 \mathrm{~km}$ depth and accumulated $5-10 \mathrm{~km}$ of 139 displacement during the Middle Miocene - Lower Pliocene (Collettini et al., 2013; Tesei et al., 140 2013). Monte Maggio fault is an oblique-normal fault with estimated fault exhumation of $\sim 2 \mathrm{~km}$ 141 and a total displacement of $\sim 650 \mathrm{~m}$, which likely accumulated during upper Pliocene to 142 Quaternary (Collettini et al., 2014). The fault cuts through the massive limestones of Calcare 143 Massiccio Formation of Lower Jurassic.

144 2.2. STATIC HEATING 
145 To investigate the effect of short period heating on $\Delta_{47}$ values, we conducted a series of static

146 heating experiments of short duration (seconds) and long duration (72 hours) using KG powder

147 samples. We examined the effects of maximum temperature $\left(\mathrm{T}_{\max }\right)$ and cooling rate on short

148 heating duration samples. Powdered KG limestone $(105<\mathrm{d}<250 \mu \mathrm{m})$ was vacuum dried at 50

$149{ }^{\circ} \mathrm{C}$ and 50-200 mg aliquots were heated inside gold capsules, to which a thermocouple was

150 attached. In general, the capsules were closed but not sealed (see section 1.1.1 in supplementary

151 material; SM) and therefore were exposed to ambient room conditions. Detailed experimental

152 conditions are given in Table 1 and in SM (section 1.1.1, 1.1.2, Table S1, and Figs. S1-S4).

\subsection{ROCK SHEAR EXPERIMENTS}

\subsubsection{EXPERIMENTAL PROCEDURE}

155 The experiments were conducted using a rotary shear apparatus (ROGA) in which two rock

156 blocks are sheared through the rotation of the lower block against a static upper block (Boneh et

157 al., 2013; Reches and Lockner, 2010) (Fig. S5). The setup is capable of applying normal stresses

158 up to $35 \mathrm{MPa}$, slip velocities of 0.001 to $2 \mathrm{~m} / \mathrm{s}$, and unlimited slip distance. Both blocks were

159 ground flat, then roughened with \#600 SiC grit and dried for $\sim 24 \mathrm{hr}$ at $100{ }^{\circ} \mathrm{C}$. All experiments

160 were run at room temperature and ambient humidity. Normal load, shear load, slip velocity, fault

161 normal displacement, and block temperature were monitored continuously during the experiment

162 (Table S2).

163 We report $33 \Delta_{47}$ values of reference and sheared samples that were collected from 12 164 experimental runs using the three different carbonate rocks. After each set of experiments, the 165 following material was sampled for isotopic analysis from the sheared surface: smeared rock 166 powder that covers the slip surface (gouge), which is the product of wear by scratching, 
167 ploughing and delamination of fault surfaces that are continuously being crushed during slip;

168 delaminated flakes of FMs formed in the experiment; and reference material of undeformed rock.

170 We modeled the 3D heat conduction in the shear experiments to calculate the temperature at

171 the slip surface. The model assumes that all the mechanical work is converted into heat (Rice,

172 2006), and that conduction is the only mechanism of heat transfer within the rock blocks. The

173 heat source time evolution is the experimental mechanical power density, $\mathrm{PD}=\tau(\mathrm{t}) \cdot \mathrm{v}(\mathrm{t})$ (units of

$174 \mathrm{~W} / \mathrm{m}^{2}$ ), which was calculated from the experimental record of slip velocity, $\mathrm{v}$, and shear stress, $\tau$.

175 The model was validated by temperature measured at two positions embedded within the 176 stationary block (Fig. S6).

177 The temperature experienced by the experimental fault and its surrounding was simulated 178 using the COMSOL Multiphysics software. The 3D finite-element model of the experimental 179 fault structure considers a boundary condition of a planar heat source in the middle of a $100 \mu \mathrm{m}$ 180 thick gouge layer bound by two solid rock blocks. This structure follows the post shear structure 181 of the high-velocity experiments that displayed an ultrathin slip surface $(\sim 1 \mu \mathrm{m})$ within the gouge 182 layer (Siman-Tov et al., 2015). Variability in mechanical and thermal parameters (specific heat 183 capacity, coefficient of thermal conductivity, rock density) as well as structural and measurement 184 errors produce an error of up to $15 \%$ in modeled temperature. More details about the model and 185 its constraints are given in section 1.2.2 of the SM and in Table S3. 
189 event. The field samples of mirror surfaces were carefully scraped with a scalpel to collect only

190 the PSZ layer of the reflective surfaces, which is less than $10 \mu \mathrm{m}$ thick. These PSZ samples were

191 compared with reference samples of the non-sheared source rock. The KG reference was an

192 Eocene limestone from Bar-Kokhba Formation. The reference samples for Spoleto and Monte 193 Maggio faults are respective samples of Calcare Massiccio limestone collected in the damage 194 zone far $(>10 \mathrm{~cm})$ from the PSZ layer.

All three types of samples were analyzed for $\delta^{13} \mathrm{C}, \delta^{18} \mathrm{O}$ and $\Delta_{47}$ using standard procedures (Ghosh et al., 2006; Huntington et al., 2009). Briefly, 4 $\mathrm{mg} \mathrm{CaCO}_{3}$ was digested overnight in

$198103 \% \mathrm{H}_{3} \mathrm{PO}_{4}$ at $25^{\circ} \mathrm{C} . \mathrm{CO}_{2}$ was extracted cryogenically on a vacuum line and cleaned by passing 199 it through a GC column (Supelco Q-Plot, $30 \mathrm{~m} \times 0.53 \mathrm{~mm}$, held at $-20^{\circ} \mathrm{C}$ ). Measurements were 200 performed using a Thermo MAT-253 gas source isotope ratio mass spectrometer that was 201 modified to measure masses 44-49 in a dual inlet mode. Each measurement consisted of 90 202 cycles of sample-standard comparison, with a signal integration time of $8 \mathrm{~s}$.

$203 \Delta_{47}$ is defined as the excess of the mass 47 signal in $\mathrm{CO}_{2}$ over what is expected based on 204 random distribution of ${ }^{13} \mathrm{C}$ and ${ }^{18} \mathrm{O}$ among all $\mathrm{CO}_{2}$ isotopologues (Eiler, 2007; Wang et al., 2004):

$$
\Delta_{47}=\left[\left(\frac{R_{47}}{R_{47}^{*}}-1\right)-\left(\frac{R_{46}}{R_{46}^{*}}-1\right)-\left(\frac{R_{45}}{R_{45}^{*}}-1\right)\right] \times 1000
$$
values for isotopologues at random distribution.

208 Data is reported in the absolute reference frame. Overall standardization is done using $\mathrm{CO}_{2}$ at 209 equilibrium at several temperatures and tested day-to-day using materials that are traceable to that 
210 reference frame (Zaarur et al., 2013). The typical Yale laboratory uncertainty is $\pm 0.02 \%$ for a

211 non-replicated sample. The uncertainty for our data set is estimated from 5 replicates of 1 sample

212 (\# 2055) as $\pm 0.012 \%$ ( $\pm 1 \mathrm{SE}$ ), which is slightly higher than usual.

$213 \quad \delta^{18} \mathrm{O}$ and $\delta^{13} \mathrm{C}$ values, are reported versus the VPDB standard reference frame using a pre-

214 calibrated $\mathrm{CO}_{2}$ tank used as a reference gas, with values of $-15.80 \%$ and $-3.64 \%$ for $\delta^{18} \mathrm{O}$ and

$215 \delta^{13} \mathrm{C}$, respectively. These values are verified using the standard NBS-19 with measured $\delta^{18} \mathrm{O}$ and

$216 \delta^{13} \mathrm{C}$ values of $-2.17 \pm 0.04 \%$ and $+2.11 \pm 0.13 \%$ ( $\left.1 \mathrm{SD}, \mathrm{n}=12\right)$, respectively, which are

217 comparable to its nominal values of $-2.2 \%$ and $+1.95 \%$ (Zaarur et al., 2013). Oxygen isotopic

218 fractionation factors associated with the acid digestion reaction at $25{ }^{\circ} \mathrm{C}$ is taken as ${ }^{18} \alpha_{\text {acid }}=$

2191.01030 for calcite (Kim et al., 2007).

220 3. RESULTS

\section{1. $\Delta_{47}$ VALUES UNDER STATIC HEATING}

222 Samples heated at $\mathrm{T} \leq 400{ }^{\circ} \mathrm{C}$ display $\Delta_{47}$ values similar to those of the reference, unheated, 223 samples (0.64-0.67 \%; Fig. 1). In contrast, samples held for a few seconds at temperatures 224 between 500 and $1,000{ }^{\circ} \mathrm{C}$ show a decrease in $\Delta_{47}$ values (Fig. 1, Table S4), to values of 0.24 $2250.32 \%$ at $\mathrm{T} \geq 800{ }^{\circ} \mathrm{C}$ (e.g., experiments D102-107, blue circles in Fig. 1), similar to values 226 observed in longer heating ( 3 min -44 days) at $\mathrm{T}>500{ }^{\circ} \mathrm{C}$ (Passey and Henkes, 2012; Stolper 227 and Eiler, 2015), reflecting randomization (or close to it) of the isotopes.

228 Our observations of very low $\Delta_{47}$ values for short heating events suggest that at these high 229 temperatures, short heating is sufficient for randomization of the isotopes. No significant 230 difference was observed in $\Delta_{47}$ values between experiments in which cooling was rapid (by 231 dropping the capsules into liquid nitrogen; \# D201-D208, green diamonds in Fig. 1), and 
232 experiments in which cooling was slower (\# D401-D408, black squares in Fig. 1), suggesting that 233 cooling rates at these short time scales have no effect on the final $\Delta_{47}$ value. The maximal

234 temperature in which the sample was held and the time spent at that temperature are the major 235 controlling factors on the $\Delta_{47}$ values (Fig. 1). An effect of heating duration was observed in

236 samples heated to $400{ }^{\circ} \mathrm{C}$. The short heating experiments (\# D205 and D405) show no change in $237 \Delta_{47}$ value, but $\Delta_{47}$ decreased by $0.1 \%$ when the sample was heated for 72 hours. No significant 238 difference is observed between samples heated with or without added water (\# D101-D103 and 239 \# D106-D107 versus \# D104-D105). No difference in $\Delta_{47}$ was observed between sealed (\# D106240 D107) or unsealed capsules (\# D102-D103) in the early experiments, so all further experiments 241 were conducted in closed but not sealed capsules.

242 Although $\Delta_{47}$ values decreased with increasing temperature, $\delta^{13} \mathrm{C}$ and $\delta^{18} \mathrm{O}$ values remained 243 unchanged in all short duration ( 10s of seconds) heating experiments (Fig. 1), as has also been 244 observed in calcite heating for longer times (Henkes et al., 2014; Passey and Henkes, 2012; 245 Stolper and Eiler, 2015). At 72 hours heating experiments (\# D304-D305 in Fig. S3) at T $\geq 600$ $246{ }^{\circ} \mathrm{C}$ a decrease in $\delta^{13} \mathrm{C}$ (from -4.5 to $-14.6 \%$ ) and $\delta^{18} \mathrm{O}$ (from -9.5 to $-22.5 \%$ ) was observed, 247 together with observed mass loss resulting from calcite thermal decomposition (Fig. 1). In our 248 experiments, calcite decomposition most likely occurred because the samples were heated at 249 room conditions, unlike previous experiments that were conducted under a $\mathrm{CO}_{2}$ atmosphere 250 (Henkes et al., 2014; Passey and Henkes, 2012; Stolper and Eiler, 2015). During thermal 251 decomposition of calcite the heavy isotopes are preferentially partitioned into the $\mathrm{CO}_{2}$ released, 252 leaving more depleted calcite crystals (De Paola et al., 2011). In these experiments $\Delta_{47}$ values 253 were surprisingly high ( 0.50 and $1.07 \%$ at 600 and $800{ }^{\circ} \mathrm{C}$, respectively), likely reflecting 254 fractionation during thermal decomposition or inefficient acid digestion of these samples perhaps 
255 due to the presence of $\mathrm{CaO}$. These samples therefore do not reflect the influence of heating and

256 are not discussed further. In summary, a decrease in $\Delta_{47}$ values occurs within seconds in

257 carbonate solids heated to temperatures $\geq 500{ }^{\circ} \mathrm{C}$ and thus potentially provide an indicator for

258 very short heating events, such as in earthquakes when fault slip and associated release of heat 259 occurs within a few seconds.

\subsection{ISOTOPIC COMPOSITION IN ROCK SHEARING EXPERIMENTS}

261 Three types of limestone (Brown Lueders, Dover Gray, and Kfar Giladi) were used for rock

262 shear experiments at velocities of $0.001-0.63 \mathrm{~m} / \mathrm{s}$, at applied normal stress up to $3.1 \mathrm{MPa}$ and slip 263 time up to 1,000 s (Table S2). Values of $\Delta_{47}$ determined for 33 samples are listed in Table S5 and 264 plotted in Figs. 2-4. Temperature modeling (see methods section 2.3.2) indicates that the 265 maximal temperature $\left(\mathrm{T}_{\max }\right)$ that the samples were exposed to in these shear experiments was 420

$266{ }^{\circ} \mathrm{C}$ (Fig. 4). For the BL limestone (experiments \# 1865 and 1873 in Table S5) $\delta^{13} \mathrm{C}$ is $1.04 \pm 0.06$ $267 \%$, $\delta^{18} \mathrm{O}$ is $-4.44 \pm 0.18 \%$ and $\Delta_{47}$ range between $0.46-0.66 \%$ (Fig. 2, and Table S5). The 2 268 higher values $(0.63 \pm 0.02 \%$ ) correspond to reference and gouge samples, whereas 5 lower values 269 (0.53 $\pm 0.05 \%$ \%) correspond to the FMs (Fig. 3). For DG (experiment \# 2050-2062 and \# 2287) $270 \quad \delta^{13} \mathrm{C}$ is $0.9 \pm 0.2 \%, \delta^{18} \mathrm{O}-2.9 \pm 0.6 \%$ and $\Delta_{47}$ values range between $0.51-0.71 \%$ (Fig. 2). The 8

271 higher values $(0.67 \pm 0.04 \%)$ correspond to reference and some gouge samples, whereas the 4 272 lower values $(0.54 \pm 0.02 \%)$ correspond to other gouge samples and to FM samples (Fig. 3). For 273 KG (experiment \# 1840-1855 and \# 1880-1892) $\delta^{13} \mathrm{C}$ is $-7.3 \pm 0.2 \%$, $\delta^{18} \mathrm{O}-9.6 \pm 0.3 \%$ and $\Delta_{47}$ 274 values range between 0.54-0.74 \%o (Fig. 2), with no obvious correlation with sample types (Fig. 275 3). Fig. 4 plots all experimental results as function of $T_{\max }$, showing that $\Delta_{47}$ drops with increasing $276 \mathrm{~T}_{\max }$ but also that this drop in $\Delta_{47}$ may start already at low $\mathrm{T}_{\max }\left(<150{ }^{\circ} \mathrm{C}\right)$. 
The $\Delta_{47}$ values in three different limestone faults range from 0.65 to $0.73 \%$ (Fig. 5 and Table

S6). No significant difference in $\Delta_{47}$ or $\delta^{13} \mathrm{C}$ and $\delta^{18} \mathrm{O}$ values is observed between the slip

280 surfaces and the respective undeformed reference host rock. In the KG quarry the $\Delta_{47}$ values for

281 both slip surface and host rock are $0.65-0.68 \%$. The values of $\delta^{13} \mathrm{C}\left(-4.5\right.$ to $-5.9 \%$ and $\delta^{18} \mathrm{O}$

282 (-8.8 to $-9.9 \%$ ) for both slip surfaces and host rock, are consistent with previous host rocks

283 measurements (Nuriel et al., 2012b). In the Spoleto and Monte Maggio faults (Italy), the $\Delta_{47}$

284 values are $0.71-0.73 \%$, for both fault surfaces and host rock. For Spoleto fault $\delta^{13} \mathrm{C}$ is between

2850.1 and $1.0 \%$ and $\delta^{18} \mathrm{O}$ is $\sim-4.5 \%$ (Fig. 5). For Monte Maggio fault $\delta^{13} \mathrm{C}$ is $\sim 2.0 \%$ and $\delta^{18} \mathrm{O}$ is

286 more variable, between $-3.6 \%$ and $-5.9 \%$ (Fig. 5). These values are similar to the value

287 typically reported for the limestones of Calcare Massiccio and associated veins (Agosta and

288 Kirschner, 2003; Bachan et al., 2012; Billi et al., 2007).

\section{Discussion}

\subsection{RAPID CLUMPED ISOTOPES REORDERING}

291 The observed decrease in $\Delta_{47}$ values by static heating at $\mathrm{T} \geq 500{ }^{\circ} \mathrm{C}$, accompanied by no

292 change in $\delta^{13} \mathrm{C}$ and $\delta^{18} \mathrm{O}$, indicates internal disordering of ${ }^{13} \mathrm{C}-{ }^{18} \mathrm{O}$ bonds, even at time scales of

293 seconds (Fig. 1). Disordering depends on both time and temperature (Henkes et al., 2014; Passey

294 and Henkes, 2012; Stolper and Eiler, 2015). Hence, the final $\Delta_{47}$ value observed in short heating

295 events reflects a combination of the initial $\Delta_{47}$ value, the reaction time, and the reaction rate

296 (which depends exponentially on temperature and activation energy; Fig. 6). During long heating

297 events $\Delta_{47}$ may reach an equilibrium value that depends on temperature, but is independent of the 
298 initial $\Delta_{47}$ value. In short heating events only partial disordering is observed, as samples are 299 usually cooled before reaching equilibrium (Fig. 6).

300 The change in $\Delta_{47}$ may occur either through isotope exchange between neighboring carbonates

301 within the lattice (Stolper and Eiler, 2015) or through diffusion of oxygen atoms (Passey and 302 Henkes, 2012). In either case it is a two-way process so that both disordering and ordering can 303 occur following:

$$
\mathrm{Ca}^{12} \mathrm{C}^{18} \mathrm{O}^{16} \mathrm{O}_{2}+\mathrm{Ca}^{13} \mathrm{C}^{16} \mathrm{O}_{3} \underset{k_{\text {Disorde ezgn }}}{\stackrel{k_{\text {ordering }}}{\longrightarrow}} \mathrm{Ca}^{13} \mathrm{C}^{18} \mathrm{O}^{16} \mathrm{O}_{2}+\mathrm{Ca}^{12} \mathrm{C}^{16} \mathrm{O}_{3}
$$

305 where ordering means formation of ${ }^{13} \mathrm{C}-{ }^{18} \mathrm{O}$ bonds (more clumping, defined as the forward reaction). The back reaction is disordering towards random distribution and lower $\Delta_{47}$ values. For convenience, we use here the terminology of Passey and Henkes (2012); a discussion in the terms of the Stolper and Eiler (2015) model is given below.

309 Although diffusion rate constants do not depend on process direction (Passey and Henkes, 310 2012), the reaction rate strongly depends on temperature, which in turn defines the equilibrium $311 \Delta_{47}$ value. As initial $\Delta_{47}$ values typically reflect mineral formation at low temperatures, heating 312 would lead to net disordering (i.e., the back reaction in Eq. (2)). Furthermore, whereas the 313 reaction at high temperatures is relatively fast, the reaction leading to net ordering at low 314 temperatures is much slower (Fig. 6). In two sets of experiments (\# D201-D208 and \# D401315 D408), the samples were heated within seconds and then cooled at two different rates (Figs. S2 316 and S4) with no difference in $\Delta_{47}$ values. Hence, the cooling in both cases was fast enough to 317 prevent retrograde ordering and preserve the $\Delta_{47}$ signal produced at the peak temperature (Fig. 6).

318 Static heating experiments of longer duration ( $3 \mathrm{~min}$ to 44 days) show decreasing $\Delta_{47}$ values as 319 a function of temperature and time (Fig. S7; Henkes et al., 2014 (HS); Passey and Henkes, 2012 
320 (PY); Stolper and Eiler, 2015 (S\&E)). To understand the temperature-time behavior with which

321 we can compare our short experiments, we divide the HS \& PY data into groups by heating

322 duration: 30-100 $\mathrm{min}, 100-1,000 \mathrm{~min}$, and longer than 1,000 min and compare it with our and

323 S\&E results (Fig. 7). When $\Delta_{47}$ is plotted versus maximum heating temperature, the data arrays

324 are described by a combination of exponents that take the form of an error function, in which

325 long heating times allow $\Delta_{47}$ to approach equilibrium values at lower temperatures (e.g., $\sim 200{ }^{\circ} \mathrm{C}$

326 at geological time scales versus $\sim 500{ }^{\circ} \mathrm{C}$ at laboratory time scales of hours to days). Within a

327 single temperature band (e.g., $425{ }^{\circ} \mathrm{C}$ ) longer heating duration result in lower $\Delta_{47}$ values that are

328 closer to equilibrium at that temperature, relative to short experiments.

329 Passey and Henkes (2012) derived an approximate model that considers a constant number of

330 'equilibrium defects' but neglects the initial stage of 'defect annealing'. More complete models

331 that include non first order kinetics were suggested by HS and S\&E, with two different physical

332 models to address the high disordering rates at short heating experiments. Our data is consistent

333 with both models; we compare our results to the HS 'transient defect/equilibrium defect' model

334 that considers the decrease in $\mathrm{C}-\mathrm{O}$ bond disordering rate as a result of annealing in transient

335 defects (Henkes et al., 2014). The integrated rate for this model is given by their equation 5:

$\Delta_{47}(t, T)=\Delta_{47}^{e q}(T)+\left(\Delta_{47}^{i n i t}-\Delta_{47}^{e q}(T)\right) e^{-k_{c} t} e^{\frac{k_{d}}{k_{2}}\left(e^{-k_{2} t}-1\right)}$

337 where $\Delta_{47}^{e q}(T)$ and $\Delta_{47}^{\text {init }}$ are the equilibrium $\Delta_{47}$ value at a given temperature and the initial $\Delta_{47}$

338 value, respectively. $T$ is the temperature in $\mathrm{K} . \mathrm{k}_{\mathrm{c}}, \mathrm{k}_{\mathrm{d}}$, and $\mathrm{k}_{2}$ are rate constants describing the

339 reordering behavior due to equilibrium defects, the efficacy of transient defects at inducing

340 reordering, and the loss of transient defects with time, respectively. These reaction rates $\left(k_{i}\right)$ 
341 strongly depend on the activation energies, $E_{a}$, and the ambient temperature according to an

342 Arrhenius relation (Henkes et al., 2014):

$$
k_{i}=K_{i} e^{-\left(E_{i} / R\right)}
$$

344 where $K_{i}$ is a constant known as the frequency factor and $R$ is the gas constant. $\Delta_{47}^{e q}(T)$ is the 345 equilibrium curve of $\Delta_{47}$ versus the temperature which is calculated as a fourth order polynomial

346 fit to experimental data (Equation 5 in Passey and Henkes, 2012). Using this model and the

347 Arrhenius parameters given in Table B1 in Henkes et al., (2014), we calculate expected $\Delta_{47}$

348 values for different heating durations, with our short heating experimental data being consistent 349 with these theoretical curves for 0.1-10 s (Fig. 7).

\subsection{SHEAR INDUCED DISORDERING}

351 The $\Delta_{47}$ values of experimentally sheared samples are lower than the reference values of the 352 undeformed rocks, with a significant decrease observed in the FMs formed in the Dover Gray and 353 Brown Lueders experiments (Figs. 2, 3). The shear experiments had a relatively low $\mathrm{T}_{\max }$ (up to $354420 \pm 65{ }^{\circ} \mathrm{C}$; Fig. 4) yet they reduced $\Delta_{47}$ signal considerably (Figs. 2,3 ). We found that the 355 average $\mathrm{T}_{\max }$ required to reduce $\Delta_{47}$ in shear experiments is $\sim 250{ }^{\circ} \mathrm{C}$, which is significantly lower 356 than $\mathrm{T}_{\max }$ required to produce a similar $\Delta_{47}$ signal in static heating experiments $\left(\geq 500{ }^{\circ} \mathrm{C}\right)$.

357 We suggest two possible explanations for the decrease in $\Delta_{47}$ values of the sheared samples:

358 (1) Thermal Effects: It is possible that our temperature model for $\mathrm{T}_{\max }$ underestimates the 359 actual maximum temperatures on the slip surface because it does not include possible 360 heterogeneity in shear heating. A "hot spot" instability often arises during sliding (Brown and

361 Fialko, 2012) and when this happens it significantly increase local $\mathrm{T}_{\max }$ in some places on the slip 
362 surface, while reducing $\mathrm{T}_{\max }$ in adjacent locations, a few millimeters away. This instability, well

363 known in engineering, was recently suggested to cause formation of FM patches (Siman-Tov et

364 al., 2015). The spatial fluctuations due to hot spot instability was measured by Brown and Fialko,

365 (2012) to be up to $\pm 100{ }^{\circ} \mathrm{C}$. Such variability is not sufficient to explain $\Delta_{47}$ reduction in shear

366 experiments observed at average $\mathrm{T}_{\max } \sim 250^{\circ} \mathrm{C}$.

367 (2) Structural Effects: Reordering processes may be enhanced at the PSZ because the 368 activation energy $\left(E_{a}\right)$ for diffusion is reduced or because of increased driving forces for diffusion

369 that increases the frequency factor $\mathrm{K}_{\mathrm{i}}$, relative to the bulk rock. The activation energy and the

370 frequency factor values may be changed by the ultra-fine grain-size in the PSZ, the high

371 abundance of defects, and the high stress and strain at grain contacts. Given the exponential

372 dependence of diffusion rates on the activation energy term, we focus on the potential effects of

373 changing it on reordering. Lower activation energy for reordering in the PSZ may considerably

374 enhance $\Delta_{47}$ changes both during and after slip and may thus affect natural faults over geological

375 times (see section 4.3).

$376 \quad E_{a}$ is expected to be lowered in the PSZ via several processes: Mechanical milling during shear

377 of fault surfaces induces accumulation of defects, increases the relative proportion of grain

378 boundaries, and reduces grain size to the nano-scale (Koch, 1997; Siman-Tov et al., 2013).

379 Atomic diffusion is enhanced both within the bulk of the lattice due to internal defects and on

380 surfaces due to the large number of grain boundaries. A grain size effect on $E_{a}$ arises in

381 nanograins because they have a much higher free energy than $>1 \mu \mathrm{m}$ crystals, due to their large

382 surface to volume ratio (Guisbiers and Buchaillot, 2008; Sun, 2007).

383 In addition, we propose, based on previous studies in other stressed materials (e.g. Brune et 384 al., 1995; Muller and Saul, 2004; Shu et al., 2001), that high stress and strain at grain surfaces 
within the PSZ may reduce the activation energy for surface diffusion. This effect is significant;

386 in metals a $5 \%$ strain was measured to cause a 3 fold reduction in $\mathrm{E}_{\mathrm{a}}$ for surface diffusion (e.g.

387 Brune et al., 1995). Thus in a PSZ fault, the structural effect includes high shear stress and strain,

388 nano-size grains, and an increase of defect concentration, the combination of which can lower the

389 activation energy relative to $\mathrm{E}_{\mathrm{a}, \text { bulk }}$. Such reduction may allow rapid reordering kinetics within the

390 fault, even at relatively low temperatures. For example, if $\mathrm{E}_{\mathrm{a}, \mathrm{PSZ}}=0.5 \mathrm{E}_{\mathrm{a}, \text { bulk }}$ and $\mathrm{E}_{\mathrm{a} \text {,bulk }}=180$

$391 \mathrm{~kJ} / \mathrm{mol}$, the structural effect increases the atomic mobility by 15 orders of magnitude at $\mathrm{T}=50$

$392{ }^{\circ} \mathrm{C}$, and by 6 orders of magnitude at $\mathrm{T}=500{ }^{\circ} \mathrm{C}$. This mechanism may be significant for both co-

393 slip and post-slip clumped isotopes reordering, since it does not require the actual slip motion;

394 once the PSZ material have been milled to nanograins and as long as shear stress is applied on the

395 PSZ, or if shear strain is not relaxed, $\mathrm{E}_{\mathrm{a}, \mathrm{PSZ}}<\mathrm{E}_{\mathrm{a}, \text { bulk }}$ leading to high reordering rates also in the

396 absence of high temperature.

397 The structural effect may increase reordering rates irrespective of the physical model used to

398 describe the disordering during heating (Henkes et al., 2014; Stolper and Eiler, 2015). The

399 Henkes et al. (2014) model suggests that reordering is driven by defects. As such, an increase of 400 defect concentration by milling directly enhances reordering rates. In addition, high shear stresses 401 and strains may mobilize defects at higher rates and enhance reordering. Stolper and Eiler (2015) 402 suggest a deficit of carbonate pairs that each includes one heavy isotope (namely, neighboring $403{ }^{13} \mathrm{C}^{16} \mathrm{O}_{3}$ and ${ }^{12} \mathrm{C}^{16} \mathrm{O}_{2}{ }^{18} \mathrm{O}$ ) as a reason for the fast reordering in short heating durations, with the 404 formation of such pairs in longer times leading to a decrease in disordering rates. The formation 405 of ${ }^{13} \mathrm{C}^{16} \mathrm{O}_{3^{-}}{ }^{12} \mathrm{C}^{16} \mathrm{O}_{2}{ }^{18} \mathrm{O}$ pairs over time requires long range diffusion of carbonate units which is 406 likely to occur through defects, and therefore may also be enhanced by an increase in defect 407 concentrations in the nano-size grains following shear. 
408 We calculated $\Delta_{47}$ using a variety of $\mathrm{E}_{\mathrm{a}, \mathrm{PSZ}}$ values, assuming different heating temperatures

409 and different heating durations (Fig. 8). The $\Delta_{47}$ signal measured for the experimentally sheared

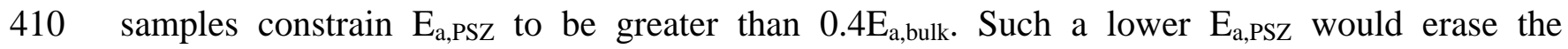

411 disordering signal within a few minutes, which is the duration the sample remained under stress

412 after the experiments. We therefore plot the model results for $\mathrm{E}_{\mathrm{a}, \mathrm{PSZ}}=0.5 \mathrm{E}_{\mathrm{a} \text {,bulk }}$ (reduced $\mathrm{E}_{\mathrm{a}}$ for $\mathrm{k}_{\mathrm{c}}$

413 and $\mathrm{k}_{\mathrm{d}}$ in Equation 3) assuming it is the maximum possible decrease in $\mathrm{E}_{\mathrm{a}}$. As a sensitivity test we

414 add the model results for $\mathrm{E}_{\mathrm{a}, \mathrm{PSZ}}=0.9 \mathrm{E}_{\mathrm{a}, \mathrm{bulk}}$, which show insignificant effect on $\Delta_{47}$ values.

415 In summary, we discussed two possible mechanisms for disordering during shear: 1) reduction 416 of the activation energy or 2) non homogeneous heating. The thermal effect is ignored in the next

417 section in which we discuss post-slip periods, and concentrate on the structural effects for 418 geological time scales.

\section{4.3. REORDERING ALONG NATURAL FAULTS}

420 Reduction in $\Delta_{47}$ values is observed in most shear experiments (Fig. 2) yet samples collected 421 from natural carbonate FMs show no difference in $\Delta_{47}$ values between FMs and host rock 422 material (Fig. 5). As FMs are the most deformed part of a fault zone the lack of observed change 423 in $\Delta_{47}$ in these natural FMs may indicate either that disordering did not occur in the natural faults 424 that we examined, or that the disordering signature was lost in post-slip processes.

425 It is possible that co-slip temperature conditions in these natural faults did not produce 426 significant clumped isotope disordering, either because $\mathrm{T}_{\max }$ was not high enough or it was not 427 sustained for long enough time. This is, however, unlikely since at least for the Spoleto fault 428 (Collettini et al., 2013) there is independent evidence for high temperature $\left(>600{ }^{\circ} \mathrm{C}\right)$ and heating 429 duration sufficiently long to allow calcite dissociation. Slip during earthquakes is likely shorter 
430 than in some of our laboratory experiments (a few seconds in nature versus 0.5-60 $\mathrm{s}$ in the

431 laboratory). However, extensive FM coverage as found in our sampled faults is believed to form 432 only at high slip velocities and temperatures (Fondriest et al., 2013; Siman-Tov et al., 2015;

433 Smith et al., 2013). It is noteworthy however, that recent studies show the formation of shiny 434 patches also in room temperature experiments: under a normal stress of $50 \mathrm{MPa}$ at low velocity $435(\mathrm{v} \sim 1 \mu \mathrm{m} / \mathrm{s})$, without significant heating during a slip event (Verberne et al., 2014a, 2014b) and 436 therefore no expected isotopic disordering. Yet those experimentally observed low velocity FMs 437 show sub-micron-structures that are different than the high velocity FMs, and also present very 438 small lateral continuity (De Paola et al., 2015; Siman-Tov et al., 2015) which is different than the $439 \quad$ FM examined here.

440 Another possible reason for lack of $\Delta_{47}$ signal is that coarse sampling may lead to mixing of 441 FM material with less sheared material. Our sampling method was the same in the shear 442 experiments and in natural faults, arguing against a methodological reason for the lack of $\Delta_{47}$ 443 decrease in natural faults.

444 We thus deduce that disordering of clumped isotopes likely occurred during the seismic slip, 445 similar to that in our shear experiments, but was followed by post-slip processes that erased this 446 signal. As the shiny surface characteristic of FM sintered nanograins texture (Siman-Tov et al., 447 2013) is preserved, it is unlikely that the sheared material has been removed by weathering or 448 altered by recrystallization of the calcite, which would coarsen the grains and alter $\delta^{13} \mathrm{C}$ and $\delta^{18} \mathrm{O}$, 449 both of which are not observed.

450 A post-slip mechanism that may increase the rate of reordering at low temperatures in the FM 451 and increase $\Delta_{47}$ values in the natural faults requires a reduction in activation energy at the fault 452 surface $\left(\mathrm{E}_{\mathrm{a}, \mathrm{PSZ}}<\mathrm{E}_{\mathrm{a} \text {,bulk }}\right)$. Such reduction may be the result of nanograin FM texture, high 
453 concentration of crystal defects, and the high shear stress and strain on contacts within the fault

454 PSZ, making the PSZs more reactive than the bulk. This mechanism was discussed above as 455 promoting disordering at relatively low temperatures during shear experiments, but is also 456 relevant for post-slip ordering. Within minutes after the slip event, the PSZ temperature decreases 457 back close to pre-slip ambient temperatures. For the minerals away from the PSZ, with kinetics 458 controlled by $\mathrm{E}_{\mathrm{a} \text {,bulk }}$, more than $100 \mathrm{Ma}$ would be required to reach $\Delta_{47}$ equilibrium values at these 459 low temperatures (Fig. 7). In the PSZ, however, where $\mathrm{E}_{\mathrm{a}}$ is likely reduced, ordering rates may be 460 faster by orders of magnitude. For example, an increase of $\Delta_{47}$ from $0.45 \%$ o to an equilibrium 461 value of $0.65 \%$ by ordering takes: $>100$ Ma for $\mathrm{E}_{\mathrm{a}, \mathrm{PSZ}}>0.8 \mathrm{E}_{\mathrm{a} \text {,bulk }}$ but $\sim 100 \mathrm{ka}$, for $\mathrm{E}_{\mathrm{a}, \mathrm{PSZ}}=$ $462 \sim 0.7 \mathrm{E}_{\mathrm{a}, \text { bulk. }}$. These are the time scales that are relevant for the $\mathrm{KG}$ fault, in which structural 463 evidence suggests no seismic activity since 93 ka BP (Nuriel et al., 2012a).

464 We emphasize that the above arguments pertain to the very thin FM within the PSZ, where the 465 intense shear heating takes place within nanograin layer. These arguments do not pertain to 466 measurements made away from PSZs. For example, Swanson et al. (2012) studied $\Delta_{47}$ values up 467 to 1 meter away from a detachment fault plane, at a distance where shear heating is unexpected. 468 The low values measured by Swanson et al. (2012) were attributed to mineral precipitation from 469 hot fluids.

470 In contrast to our observations, a significant reduction in $\Delta_{47}$ was found in shear zone samples 471 from the Mormon Peak and the Heart Mountain detachments (Swanson, 2015). These structures 472 were described either as detachments at the base of giant gravity slides (Anders et al., 2006) or as 473 low angle faults (Wernicke et al., 1985). Recent analyses suggest that both structures are slides 474 rather than low angle faults (Anders et al., 2013, 2006; Goren et al., 2010) and as such are 475 suggested to have catastrophically slid for long durations and distances relative to seismic faults 
476 (Anders et al., 2010). Whereas seismic slip on faults lasts seconds, catastrophic slides occur over

477 10s of minutes to hours (Goren et al., 2010). Such slides slip for a distance of a few kilometers in

478 a single event, whereas faults slip only a couple of meters per event. The temperatures generated

479 in catastrophic gravity sliding events are much higher and maintained for a longer time so that 480 heat can be transported to a greater distance from the slip surface. These unique thermal 481 conditions are evident in the formation of a marble band and as indicators for carbonate 482 decomposition along the Heart mountain detachment plane (Anders et al., 2010; Goren et al., 483 2010). The preservation of disordered $\Delta_{47}$ signature is likely due to the higher disordering 484 intensity that occurred in this event. Furthermore, our hypothesis for rapid ordering in the PSZ is 485 consistent with the distribution of $\Delta_{47}$ signal in the Heart Mountain detachment. A marble layer 486 located away from the principal slip zone has generally lower $\Delta_{47}$ values than the gouge layer of 487 the PSZ (Swanson, 2015). It is likely that temperatures were very high all around the detachment 488 fault, leading to a decrease in $\Delta_{47}$, but ordering rates during and after cooling were much faster 489 for the small grain size in the gouge zone compared to the large marble crystals. Direct 490 comparison between simple seismically active faults and these two detachments is thus hampered 491 by their different thermal distribution, the different fault structure (Anders et al., 2013), and also 492 by the proximity of Heart Mountain and Mormon Peak detachments to volcanic sources and 493 associated hydrothermal fluids (Aharonov and Anders, 2006; Anders et al., 2006).

494 In summary, we suggest that in addition to thermal conditions, the special structure of the PSZ 495 may govern the rate of reordering. Nanograins and severely damaged and strained crystals, allow 496 for faster reordering relative to undamaged crystal lattice, at both high and low temperatures. 497 Thus although the structure of PSZ allows relatively fast disordering to occur, so that even short 
498 shear heating events produce a signal, the same PSZ structure also allows rapid ordering and 499 erasure of this signal.

500 5. CONCLUSIONS

501 Reorganization of carbon and oxygen atoms in a calcite lattice leads to disordering and 502 ordering reactions that are recorded as a change in calcite $\Delta_{47}$, with typically fast disordering at 503 high temperatures and slow ordering at low temperatures. The extent of change depends on both 504 the temperature and the duration of heat exposure. Short heating, in order of seconds, of coarse $505(105-250 \mu \mathrm{m})$ calcite grains leads to some decrease in $\Delta_{47}$ at temperatures above $500{ }^{\circ} \mathrm{C}$ and a

506 significant decrease above $700{ }^{\circ} \mathrm{C}$. Heating during shear, however, led to a significant decrease 507 already at lower temperatures (on average at $250^{\circ} \mathrm{C}$ ) in the principle slip zone that formed during 508 slip experiments. We suggest that the grinding of calcite to nanograins, the large amount of lattice 509 defects, and the high shear stress and strain on the grain contacts may reduce the activation 510 energy for these reactions and therefore enhances reordering in the lattice. Such increased rate of 511 reordering may reduce the temperature at which disordering occurs in short heating events, but 512 also may reduce the time required for ordering at low temperatures in geological settings. This is 513 consistent with disordering observed in laboratory produced fault mirrors, but this disordering is 514 erased in natural systems by ordering over a time scales shorter than a million years. Thus, owing 515 to its rapid signal decay, $\Delta_{47}$ may be a promising field marker for young seismic events. To 516 establish the validity of this hypothesis and broaden the impact of our experimental data, better 517 constraints on the effect of grain-size, defect concentration, and applied shear stresses and strains 518 are needed, and more natural fault systems should be studied. 
520 ACKNOWLEDGMENTS

521 We thank Ronit Kessel, Oded Navon, Simon Emannuel, Andrei Podelko, Yuval Boneh, and

522 Jonathan Weinstein for fruitful discussions and technical help through the research. To Andrea

523 Billi, Michele Fondriest, Luca Smeraglia, and Nicolas Beaudoin for leading us to the Italian fault

524 exposures. We further thank André Niemeijer and an anonymous reviewer for their comments.

525 This work was funded by the James S. McDonnell Foundation, NSF Geosciences Geophysics

526 award 1045414, DOI-USGS-NEHRP2011 award G11AP20008, ISF grant 1140/12 and

527 ConocoPhilips.

528 
532

533

534

535

536

537

538

539

540

541

542

543

544

545

546

547

548

549

550

551

552

553

554

555

556

557

558

559

560

561

562

563

Affek, H.P., 2012. Clumped isotope paleothermometry: Principles, applications, and challenges. In: Ivany ,L.C., Huber, B. (Eds.), Reconstructing Earth's Deep-Time Climate - The State of the Art in 2012. In: Paleontological Society Papers. 18, 101-114.

Agosta, F., Kirschner, D.L., 2003. Fluid conduits in carbonate-hosted seismogenic normal faults of central Italy. Journal of Geophysical Research 108, 2221. doi:10.1029/2002JB002013

Aharonov, E., Anders, M.H., 2006. Hot water: A solution to the Heart Mountain detachment problem? Geology 34, 165-168. doi:10.1130/G22027.1

Anders, M.H., Christie-blick, N., Walker, C.D., 2006. Distinguishing between Rooted and Rootless Detachments : A Case Study from the Mormon Mountains of Southeastern Nevada. The Journal of Geology 114, 645-664.

Anders, M.H., Fouke, B.W., Zerkle, A.L., Tavarnelli, E., Alvarez, W., Harlow, G.E., 2010. The Role of Calcining and Basal Fluidization in the Long Runout of Carbonate Slides: An Example from the Heart Mountain Slide Block, Wyoming and Montana, U.S.A. Journal of Geology 118, 577-599. doi:Doi 10.1086/656383

Anders, M.H., Schneider, J.R., Scholz, C.H., Losh, S., 2013. Mode I microfracturing and fluid flow in damage zones: The key to distinguishing faults from slides. Journal of Structural Geology 48, 113-125. doi:10.1016/j.jsg.2012.11.010

Bachan, A., van de Schootbrugge, B., Fiebig, J., McRoberts, C.A., Ciarapica, G., Payne, J.L., 2012. Carbon cycle dynamics following the end-Triassic mass extinction: Constraints from paired $\delta^{13} \mathrm{C}_{\text {carb }}$ and $\delta^{13} \mathrm{C}_{\text {org }}$ records. Geochemistry, Geophysics, Geosystems 13, Q09008. doi:10.1029/2012GC004150

Billi, A., Valle, A., Brilli, M., Faccenna, C., Funiciello, R., 2007. Fracture-controlled fluid circulation and dissolutional weathering in sinkhole-prone carbonate rocks from central Italy. Journal of Structural Geology 29, 385-395. doi:10.1016/j.jsg.2006.09.008

Boneh, Y., Sagy, A., Reches, Z., 2013. Frictional strength and wear-rate of carbonate faults during high-velocity, steady-state sliding. Earth and Planetary Science Letters 381, 127-137. doi:10.1016/j.eps1.2013.08.050

Brown, K.M., Fialko, Y., 2012. "Melt welt" mechanism of extreme weakening of gabbro at seismic slip rates. Nature 488, 638-41. doi:10.1038/nature11370

Brune, H., Bromann, K., Röder, H., Kern, K., Jacobsen, J., Stoltze, P., Jacobsen, K.W., Nørskov, J.K., 1995. Effect of strain on surface diffusion and nucleation. Physical Review B 52, 1314383-1325067. doi:10.1103/PhysRevB.52.R14380 
Chester, J.S., Chester, F.M., Kronenberg, A.K., 2005. Fracture surface energy of the Punchbowl fault, San Andreas system. Nature 437, 133-6. doi:10.1038/nature03942

Collettini, C., Carpenter, B.M., Viti, C., Cruciani, F., Mollo, S., Tesei, T., Trippetta, F., Valoroso, L., Chiaraluce, L., 2014. Fault structure and slip localization in carbonate-bearing normal faults: An example from the Northern Apennines of Italy. Journal of Structural Geology 67, 154-166. doi:10.1016/j.jsg.2014.07.017

Collettini, C., Viti, C., Tesei, T., Mollo, S., 2013. Thermal decomposition along natural carbonate faults during earthquakes. Geology 41, 927-930. doi:10.1130/G34421.1

De Paola, N., Chiodini, G., Hirose, T., Cardellini, C., Caliro, S., Shimamoto, T., 2011. The geochemical signature caused by earthquake propagation in carbonate-hosted faults. Earth and Planetary Science Letters 310, 225-232. doi:10.1016/j.eps1.2011.09.001

De Paola, N., Holdsworth, R.E., Viti, C., Collettini, C., Bullock, R., 2015. Can grain size sensitive flow lubricate faults during the initial stages of earthquake propagation? Earth and Planetary Science Letters 431, 48-58. doi:10.1016/j.eps1.2015.09.002

Di Toro, G., Han, R., Hirose, T., De Paola, N., Nielsen, S., Mizoguchi, K., Ferri, F., Cocco, M., Shimamoto, T., 2011. Fault lubrication during earthquakes. Nature 471, 494-8. doi:10.1038/nature09838

Eiler, J.M., 2007. "Clumped-isotope" geochemistry—The study of naturally-occurring, multiplysubstituted isotopologues. Earth and Planetary Science Letters 262, 309-327. doi:10.1016/j.eps1.2007.08.020

Fondriest, M., Smith, S.A.F., Candela, T., Nielsen, S.B., Mair, K., Di Toro, G., 2013. Mirror-like faults and power dissipation during earthquakes. Geology 41, 1175-1178. doi:10.1130/G34641.1

Ghosh, P., Adkins, J., Affek, H.P., Balta, B., Guo, W., Schauble, E.A., Schrag, D., Eiler, J.M., 2006. ${ }^{13} \mathrm{C}-{ }^{18} \mathrm{O}$ bonds in carbonate minerals: A new kind of paleothermometer. Geochimica et Cosmochimica Acta 70, 1439-1456. doi:10.1016/j.gca.2005.11.014

Goren, L., Aharonov, E., Anders, M.H., 2010. The long runout of the Heart Mountain landslide: Heating, pressurization, and carbonate decomposition. Journal of Geophysical Research 115, B10210. doi:10.1029/2009JB007113

Guisbiers, G., Buchaillot, L., 2008. Size and shape effects on creep and diffusion at the nanoscale. Nanotechnology 19, 435701. doi:10.1088/0957-4484/19/43/435701

Heard, H.C., Borg, I.Y., Carter, N.L., Raleigh, C.B., 1972. Flow and fracture of rocks. American Geophysical Union, Washington DC. 
597

598

599

600

601

602

603

604

605

606

607

608

609

610

611

612

613

614

615

616

617

618

619

620

621

622

623

624

625

626

627

628

629

630

Henkes, G.A., Passey, B.H., Grossman, E.L., Shenton, B.J., Pérez-Huerta, A., Yancey, T.E., 2014. Temperature limits for preservation of primary calcite clumped isotope paleotemperatures. Geochimica et Cosmochimica Acta 139, 362-382. doi:10.1016/j.gca.2014.04.040

Huntington, K.W., Eiler, J.M., Affek, H.P., Guo, W., Bonifacie, M., Yeung, L.Y., Thiagarajan, N., Passey, B., Tripati, A., Daëron, M., Came, R., 2009. Methods and limitations of "clumped" $\mathrm{CO}_{2}$ isotope (Delta47) analysis by gas-source isotope ratio mass spectrometry. Journal of mass spectrometry : JMS 44, 1318-1329. doi:10.1002/jms.1614

Kim, S.T., O’Neil, J.R., Hillaire-Marcel, C., Mucci, A., 2007. Oxygen isotope fractionation between synthetic aragonite and water: Influence of temperature and $\mathrm{Mg}^{2+}$ concentration. Geochimica et Cosmochimica Acta 71, 4704-4715.

Koch, C.C., 1997. Synthesis of nanostructured materials by mechanical milling: problems and opportunities. Nanostructured Materials 9, 13-22. doi:10.1016/S0965-9773(97)00014-7

McKenzie, D., Brune, J.N., 1972. Melting on fault planes during large earthquakes. Geophysical Journal of the Royal Astronomical Society 29, 65-78.

Moore, R.C., 1936. Stratigraphic classification of Pennsylvanian rocks of Kansas. Kansas Geol. Survey Bull. 22, 1-256.

Muller, P., Saul, A., 2004. Elastic effects on surface physics. Surface Science Reports 54, $157-$ 258. doi:10.1016/j.surfrep.2004.05.001

Nuriel, P., Rosenbaum, G., Zhao, J.-X., Feng, Y., Golding, S.D., Villemant, B., Weinberger, R., 2012a. U-Th dating of striated fault planes. Geology 40, 647-650. doi:10.1130/G32970.1

Nuriel, P., Weinberger, R., Rosenbaum, G., Golding, S.D., Zhao, J., Tonguc Uysal, I., BarMatthews, M., Gross, M.R., 2012b. Timing and mechanism of late-Pleistocene calcite vein formation across the Dead Sea Fault Zone, northern Israel. Journal of Structural Geology 36, 43-54. doi:10.1016/j.jsg.2011.12.010

Passey, B.H., Henkes, G. a., 2012. Carbonate clumped isotope bond reordering and geospeedometry. Earth and Planetary Science Letters 351-352, 223-236. doi:10.1016/j.eps1.2012.07.021

Reches, Z., Dewers, T., 2005. Gouge formation by dynamic pulverization during earthquake rupture. Earth and Planetary Science Letters 235, 361-374. doi:10.1016/j.epsl.2005.04.009

Reches, Z., Lockner, D.A., 2010. Fault weakening and earthquake instability by powder lubrication. Nature 467, 452-5. doi:10.1038/nature09348

Rice, J.R., 2006. Heating and weakening of faults during earthquake slip. Journal of Geophysical Research 111, B05311. doi:10.1029/2005JB004006 
Rowe, C.D., Griffith, W.A., 2015. Do faults preserve a record of seismic slip: A second opinion. Journal of Structural Geology 78, 1-26.

Scholz, C.H., 2002. The mechanics of earthquakes and faulting, 2nd ed. Cambridge University

Savage, H.M., Polissar, P.J., Sheppard, R., Rowe, C.D., Brodsky, E.E., 2014. Biomarkers heat up during earthquakes: New evidence of seismic slip in the rock record. Geology 42, 99-102. doi:10.1130/G34901.1

Shu, D.J., Liu, F., Gong, X.G., 2001. Simple generic method for predicting the effect of strain on surface diffusion. Physical Review B 64, 245410. doi:10.1103/PhysRevB.64.245410

Siman-Tov, S., Aharonov, E., Boneh, Y., Reches, Z., 2015. Fault mirrors along carbonate faults: Formation and destruction during shear experiments. Earth and Planetary Science Letters 430, 367-376. doi:10.1016/j.epsl.2015.08.031

Siman-Tov, S., Aharonov, E., Sagy, A., Emmanuel, S., 2013. Nanograins form carbonate fault mirrors. Geology 41, 703-706. doi:10.1130/G34087.1

Smith, S.A.F., Di Toro, G., Kim, S., Ree, J.H., Nielsen, S., Billi, A., Spiess, R., 2013. Coseismic recrystallization during shallow earthquake slip. Geology 41, 63-66. doi:10.1130/G33588.1

Stolper, D.A., Eiler, J.M., 2015. The kinetics of solid-state isotope-exchange reactions for clumped isotopes: a study of inorganic calcites and apatites from natural and experimental samples. American Journal of Science 315, 363-411. doi:10.2475/05.2015.01

Storti, F., Billi, A., Salvini, F., 2003. Particle size distributions in natural carbonate fault rocks: insights for non-self-similar cataclasis. Earth and Planetary Science Letters 206, 173-186.

Sun, C.Q., 2007. Size dependence of nanostructures: Impact of bond order deficiency. Progress in Solid State Chemistry 35, 1-159.

Swanson, E., 2015. Structural and clumped - isotope constraints on the mechanisms of displacement along low - angle detachments (Chapter 5). $\mathrm{PhD}$ thesis, California Institute of Technology, Pasadena, CA.

Swanson, E.M., Wernicke, B.P., Eiler, J.M., Losh, S., 2012. Temperatures and fluids on faults based on carbonate clumped-isotope thermometry. American Journal of Science 312, 1-21. doi:10.2475/01.2012.01

Tesei, T., Collettini, C., Viti, C., Barchi, M.R., 2013. Fault architecture and deformation mechanisms in exhumed analogues of seismogenic carbonate-bearing thrusts. Journal of Structural Geology 55, 167-181. doi:10.1016/j.jsg.2013.07.007 
663 Verberne, B.A., Plümper, O., de Winter, D.A.M., Spiers, C.J., 2014a. Superplastic nanofibrous slip zones control seismogenic fault friction. Science 346, 1342-4.

666 doi:10.1126/science. 1259003

Verberne, B.A., Spiers, C.J., Niemeijer, A.R., De Bresser, J.H.P., De Winter, D.A.M., Plümper, O., 2014b. Frictional properties and microstructure of calcite-rich fault gouges sheared at sub-seismic sliding velocities. Pure and Applied Geophysics 171, 2617-2640. doi:10.1007/s00024-013-0760-0

Wang, Z., Schauble, E. a., Eiler, J.M., 2004. Equilibrium thermodynamics of multiply substituted isotopologues of molecular gases. Geochimica et Cosmochimica Acta 68, 4779-4797. doi:10.1016/j.gca.2004.05.039

Weinberger, R., Gross, M.R., Sneh, A., 2009. Evolving deformation along a transform plate boundary: Example from the Dead Sea Fault in northern Israel. Tectonics 28, TC5005. doi:10.1029/2008TC002316

Wernicke, B., Walker, J.D., Beaufait, M.S., 1985. Structural discordance between neogene detachments and frontal sevier thrusts, central Mormon Mountains, southern Nevada. Tectonics 4, 213-246. doi:10.1029/TC004i002p00213

Wilson, B., Dewers, T., Reches, Z., Brune, J., 2005. Particle size and energetics of gouge from earthquake rupture zones. Nature 434, 749-752.

681 Zaarur, S., Affek, H.P., Brandon, M.T., 2013. A revised calibration of the clumped isotope thermometer. Earth and Planetary Science Letters 382, 47-57. doi:10.1016/j.eps1.2013.07.026 
686 Fig. 1. Stable isotopes response to elevated temperatures in static heating experiments. Carbonate 687 powder was heated for periods of: <26 s (diamonds and squares depict different cooling rates), $688 \sim 30 \mathrm{~s}$ (circles), and 72 hours (stars) at temperatures between 100-972 ${ }^{\circ} \mathrm{C}$ (Table 1). Samples that 689 did not experience thermal decomposition show no change in $\delta^{13} \mathrm{C}$ and $\delta^{18} \mathrm{O}$ values, whereas a 690 decrease in $\Delta_{47}$ is observed at high temperatures (see Table 1 for details).

691 Fig. 2. Isotopic data for rock samples in shear experiments. Three different limestone types were 692 sheared: Kfar Giladi (KG, red circles), Dover Grey (DG, blue squares), and Brown Lueder (BL, 693 green diamonds). Shear velocities ranged between $0.001-0.63 \mathrm{~m} / \mathrm{s}$, normal stress ranged between 694 0.4-3.1 MPa, and slip time was between 0.5-1,000 s. $\Delta_{47}$ values (A) decrease with increasing 695 shear velocity, whereas $\delta^{18} \mathrm{O}(\mathrm{B})$ and $\delta^{13} \mathrm{C}(\mathrm{C})$ values do not change.

696 Fig. 3. $\Delta_{47}$ in shear experiments depicted by material type. Reference samples were taken far from 697 the experimental slip surface. Powder samples are pulverized material formed by shear and 698 collected from the slip surface. Fault Mirror (FM) samples were scratched from FM surfaces 699 formed in shear experiments. Small symbols are data for individual samples; large symbols (with 700 error bars) are the average ( \pm 1 standard deviation) for each material and limestone type. In 701 general, $\Delta_{47}$ values of sheared materials (powder or mirror) are lower than the reference, with 702 lowest $\Delta_{47}$ values observed in Fault Mirrors.

703 Fig. 4. $\Delta_{47}$ values in shear experiments (blue squares, green diamonds, red circles) plotted versus

704 the estimated maximum temperature. Samples with similar maximum temperatures (within a 705 range of $30{ }^{\circ} \mathrm{C}$ ) were averaged (large symbols). 

squares), and Monte Maggio (green diamonds), examining differences between host rock away

708 from the fault surface (Reference), the Fault Mirror surface (up to a few micron deep), and

709 Striated Surface (only in Kfar Giladi; these are non FM, rough surfaces, with lineation indicating

710 slip direction). $\delta^{13} \mathrm{C}$ and $\delta^{18} \mathrm{O}$ values are consistent with previous measurements at all sites (blue

711 strip reflects the range observed by Nuriel et al. (2012) in Kfar Giladi; red strip is the range

712 observed in the Calcare Massiccio host rock by Bachan et al. (2012) and Billi et al. (2007) in

713 Spoleto and Monte Maggio). No significant differences are observed between Fault Mirrors and

714 Reference $\Delta_{47}, \delta^{13} \mathrm{C}$, and $\delta^{18} \mathrm{O}$ values.

715 Fig. 6. Schematic description of the clumped isotopes reordering (disordering and ordering) and

716 the path of $\Delta_{47}$ evolution during heating and cooling of a calcite sample (black dashed line).

717 When a calcite sample is subjected to high temperature, $\Delta_{47}$ will decrease from its initial value by

718 the disordering reaction (green curve). Given sufficient time at high temperature it will reach a

719 'high-temperature equilibrium' value. If, however, the heating event is short $\Delta_{47}$ would decrease

720 only to a 'lower value' but will not reach equilibrium. After cooling, $\Delta_{47}$ would follow the

721 ordering curve (blue curve). The reaction rate constants are independent of the reaction direction

722 (disordering or ordering) but temperature strongly affects the reaction rates. Therefore the

723 ordering reaction at low temperature is much slower than disordering so that a sample will

724 undergo only partial ordering but will not reach the 'low temperature equilibrium'.

725 Fig. 7. The effect of temperature and time during static heating of calcite, comparing the short

726 heating events (1-10 seconds) in this study (blue stars; TS) with longer heating in three previous

727 studies (Henkes et al., 2014 (HS); Passey and Henkes, 2012 (PY); Stolper and Eiler, 2015

$728(\mathrm{~S} \& \mathrm{E})) . \Delta_{47}$ is plotted versus the maximum temperature experienced by each sample with colored 
729 curves reflecting the approach to equilibrium (black dashed line depicts equilibrium) at different

730 time scales. Data from longer heating experiments (HS and PY) are classified by heating

731 duration: shorter than $100 \mathrm{~min}$ (purple squares), between 100-1,000 min (green circles), and

732 longer than 1,000 min (orange diamonds). Data for each time group plots along an error function

733 type shape for the relevant time scale, with higher temperature required for disordering at shorter

734 heating events. The error function shape curves (colored solid lines) depict the theoretical

735 kinetics of clumped isotopes reordering (Eq. (3)) for different heating durations; we used the

736 coefficients derived by Henkes et al. (2014) to fit $\Delta_{47}$ in Brachiopod shells heated between 30 min

737 and four days (red dots). The S\&E data are for static heating experiments, for duration of 3 min

738 to 21 days, measured in another laboratory and fits well the same general trend (black asterisks).

739 Fig. 8. $\Delta_{47}$ values in shear experiments (blue squares, green diamonds, red circles) and static

740 heating experiments (blue stars) from this study plotted versus the estimated maximum

741 temperature. Solid and dashed lines are calculated from theory. The maximum temperature was

742 calculated by a 3D model (described in section 2.3.2 and SM). Samples with similar maximum

743 temperatures (within a range of $30{ }^{\circ} \mathrm{C}$ ) were averaged (large symbols). Lines depict the

744 theoretical kinetics of the approach to equilibrium (black dashed curve) of clumped isotopes

745 reordering for three different activation energies, $E_{a, b u l k}$ (the original $E_{a}$ value estimated by

746 Henkes et al., 2014), and exampled for possible reduced activation energy: 90\% $\mathrm{E}_{\mathrm{a}, \mathrm{bulk}}$ (dashed

747 line) and $50 \% \mathrm{E}_{\mathrm{a}, \mathrm{bulk}}$ (dotted line) and two heating durations $(\mathrm{t}=1 \mathrm{~s}$ in orange and $\mathrm{t}=1,000 \mathrm{~s}$ in

748 green). The mechanisms for reduction in $\mathrm{E}_{\mathrm{a}, \mathrm{bulk}}$ in our experiments are discussed in the text. The

749 static heating results fit the predicted $\Delta_{47}$ values for heating duration of $<1 \mathrm{~s}$. Most analyses of

750 sheared samples can be explained by a $50 \%$ reduction in $\mathrm{E}_{\mathrm{a}, \mathrm{bulk}}$ in Eq. (3) $\left(0.5 \mathrm{E}_{\mathrm{a}, \mathrm{bulk}}\right) . \Delta_{47}$ values

751 are higher than the equilibrium values at the maximum temperature of exposure during the 
752 experiment, suggesting that the sheared samples have undergone only partial disordering and 753 have not reached equilibrium. 


\section{Figure 2}

O Kfar Giladi $\diamond$ Brown Lueder $\square$ Dover gray
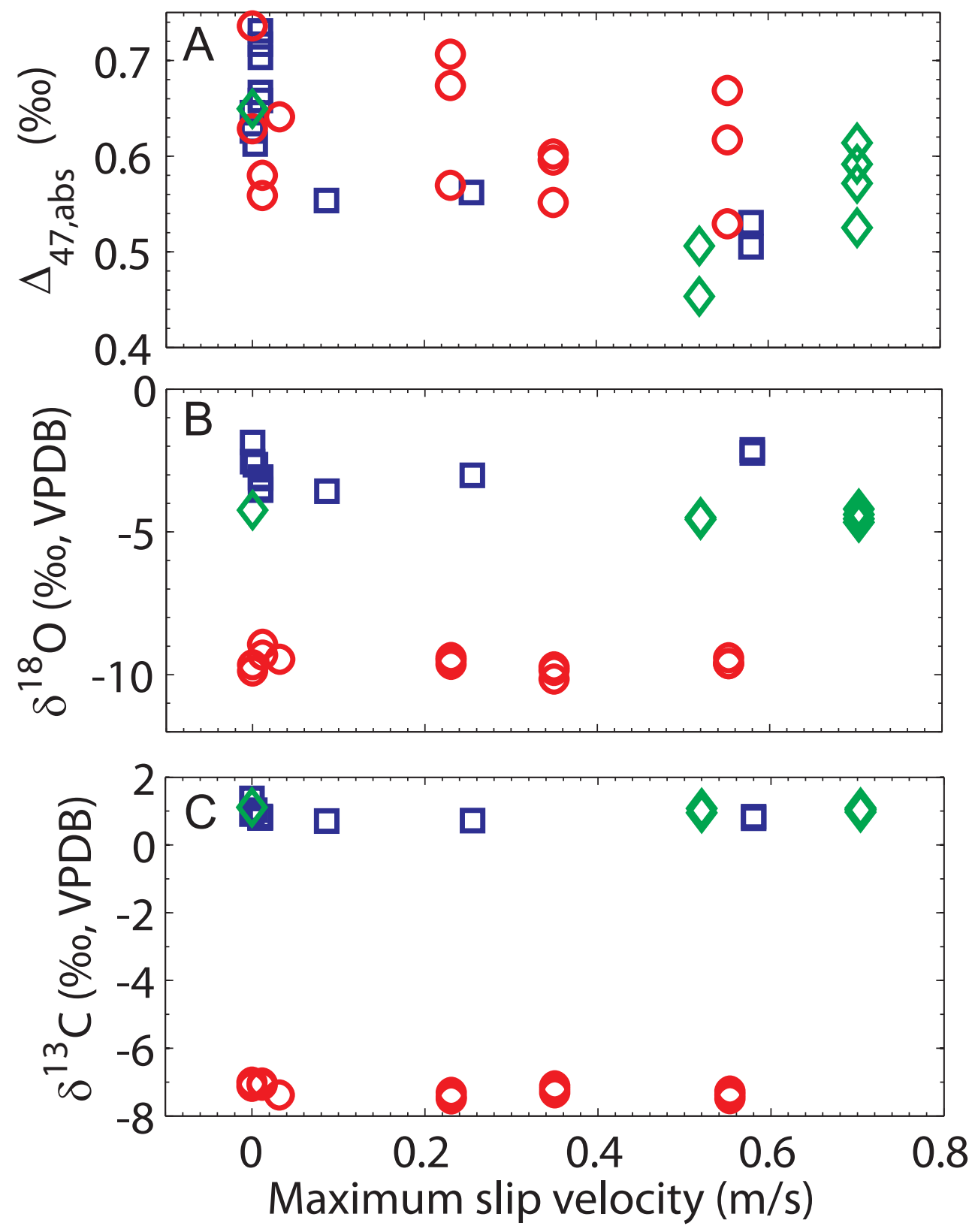


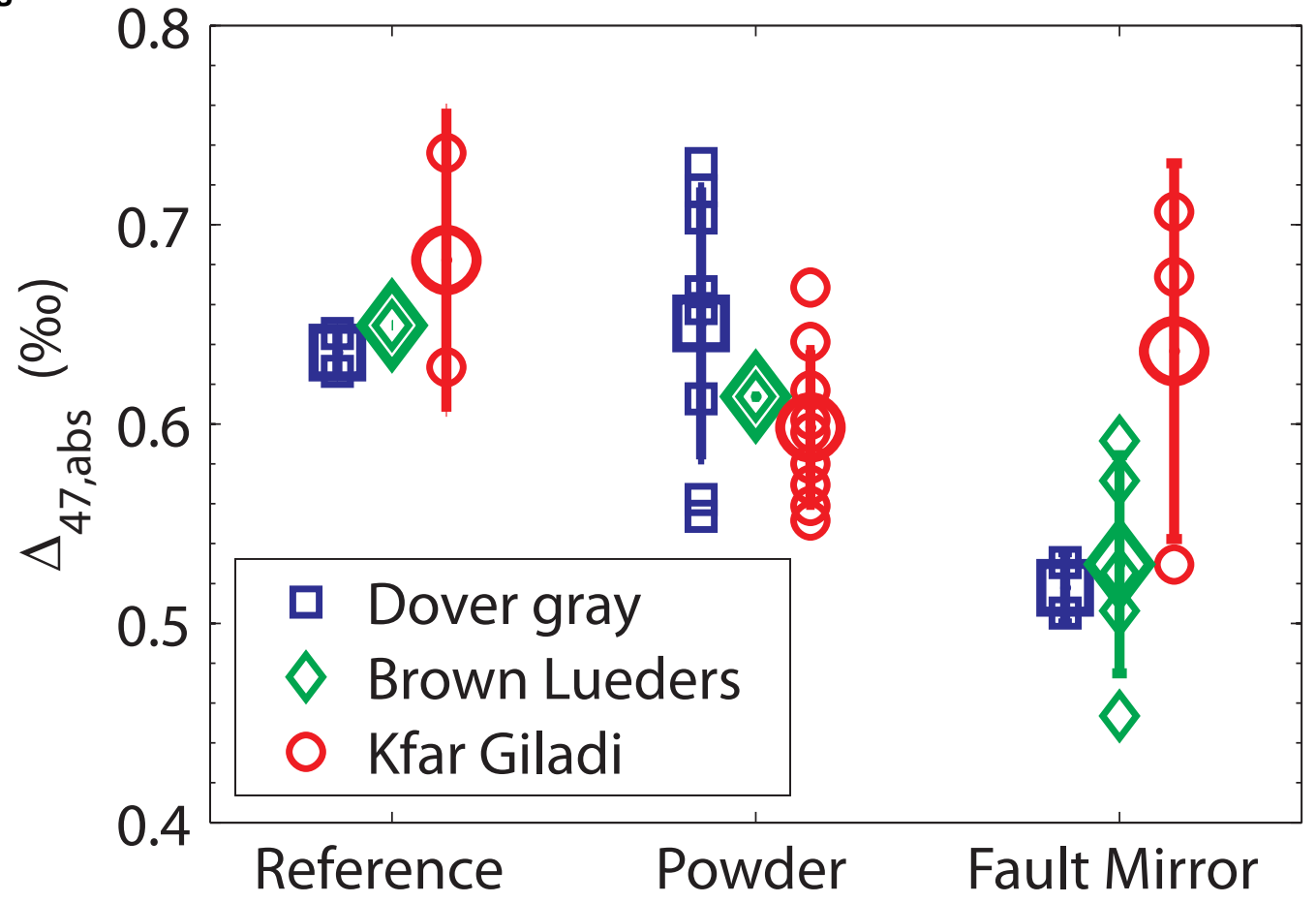


Figure 4

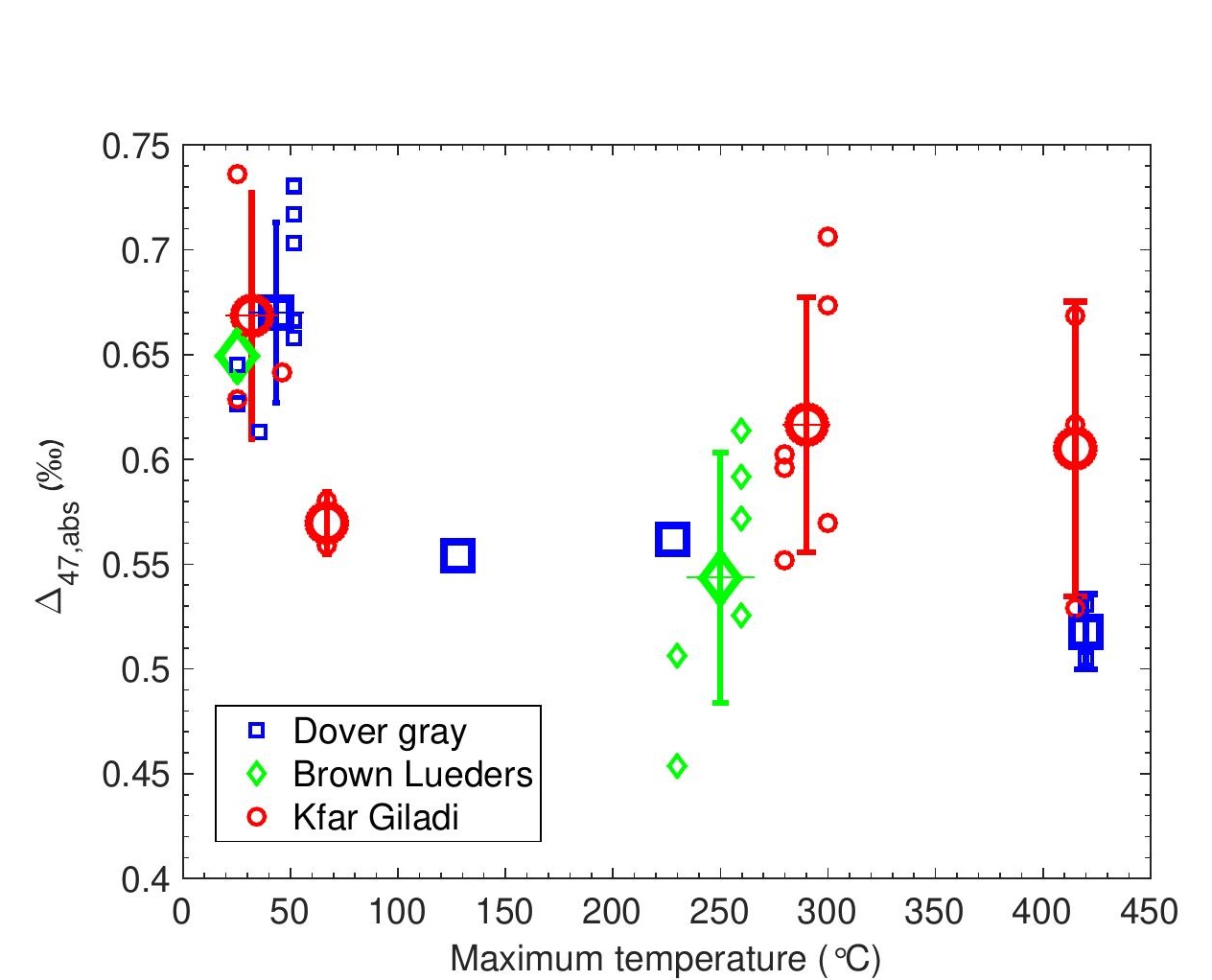

Figure

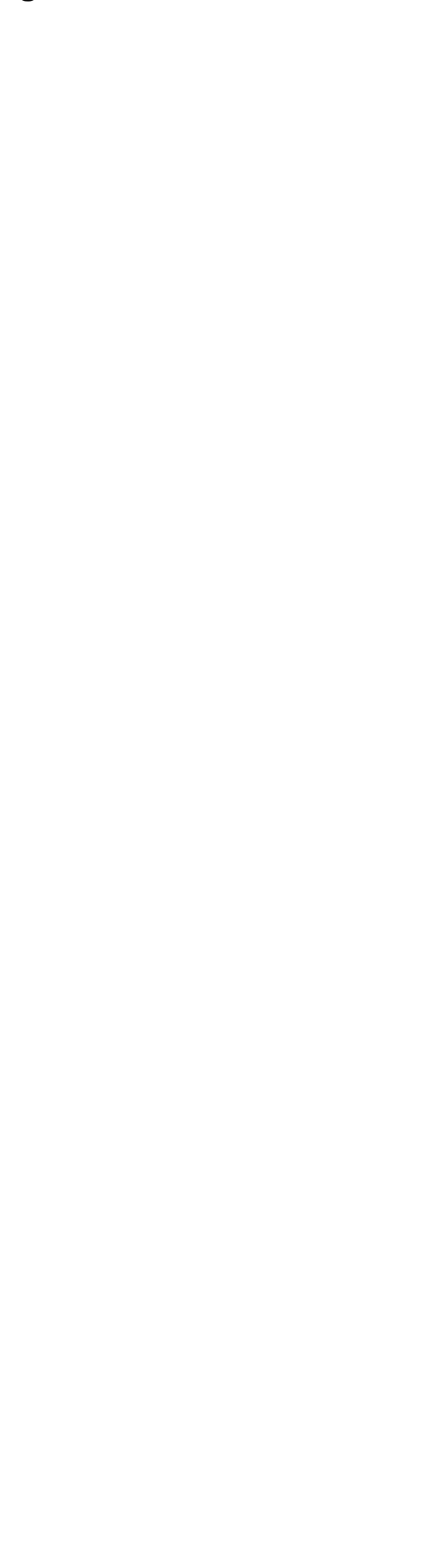

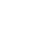

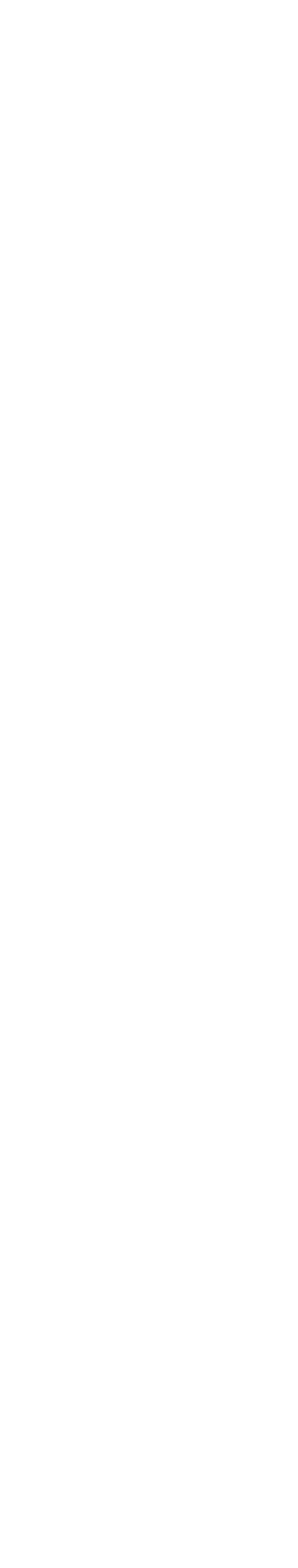


 \\ Ordering curve}

Initial value

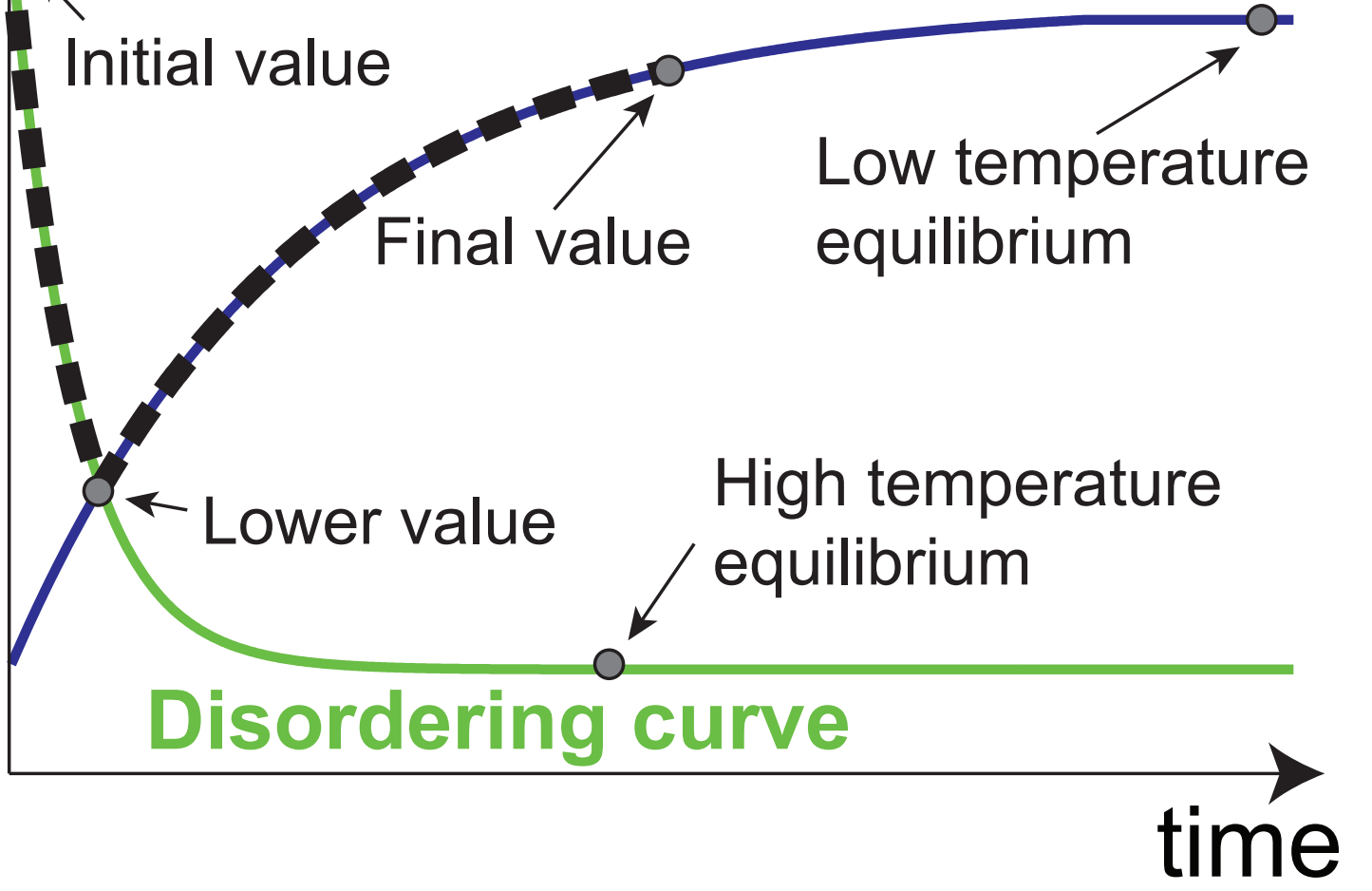


Figure 7

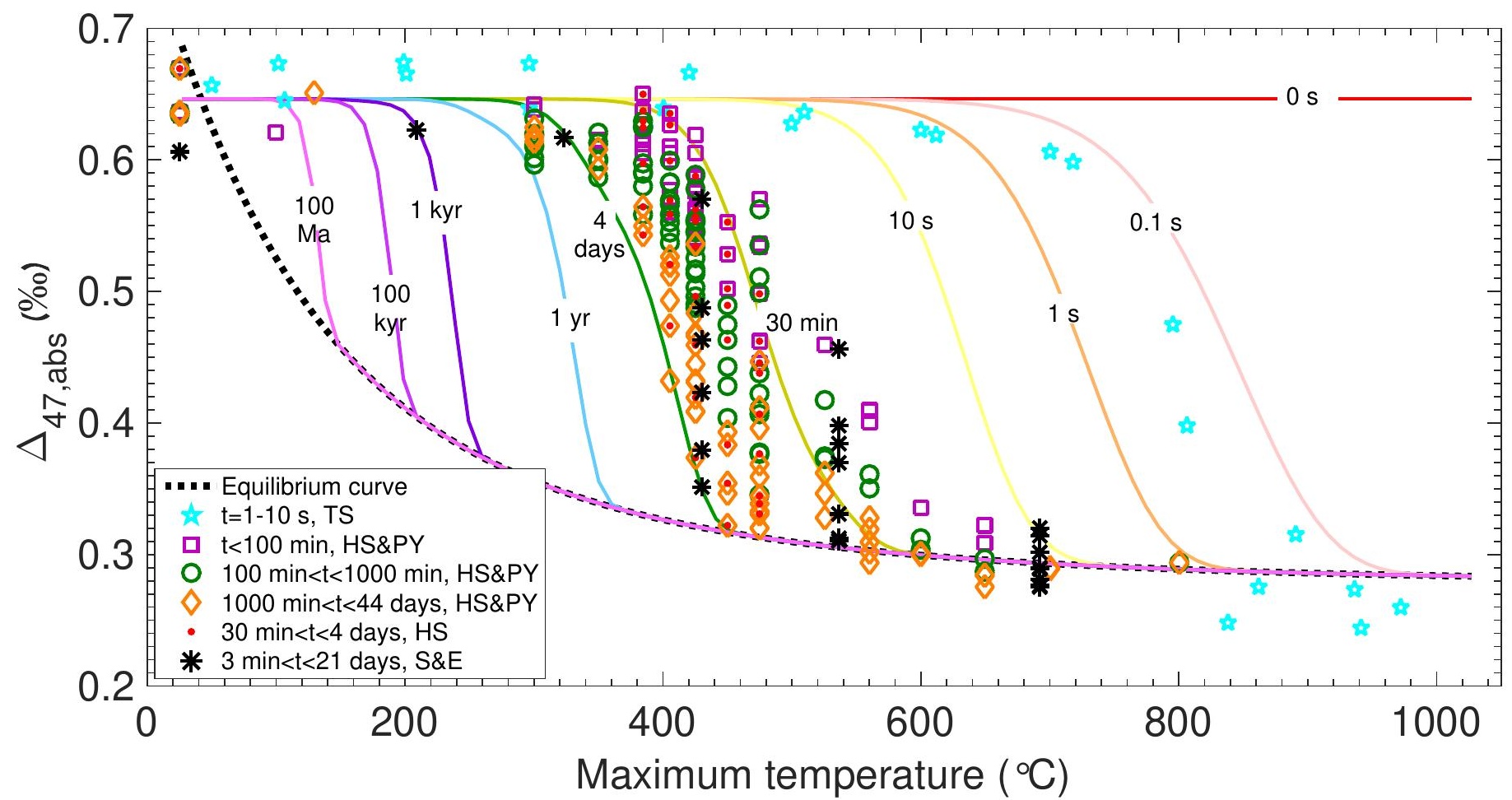


Figure 8

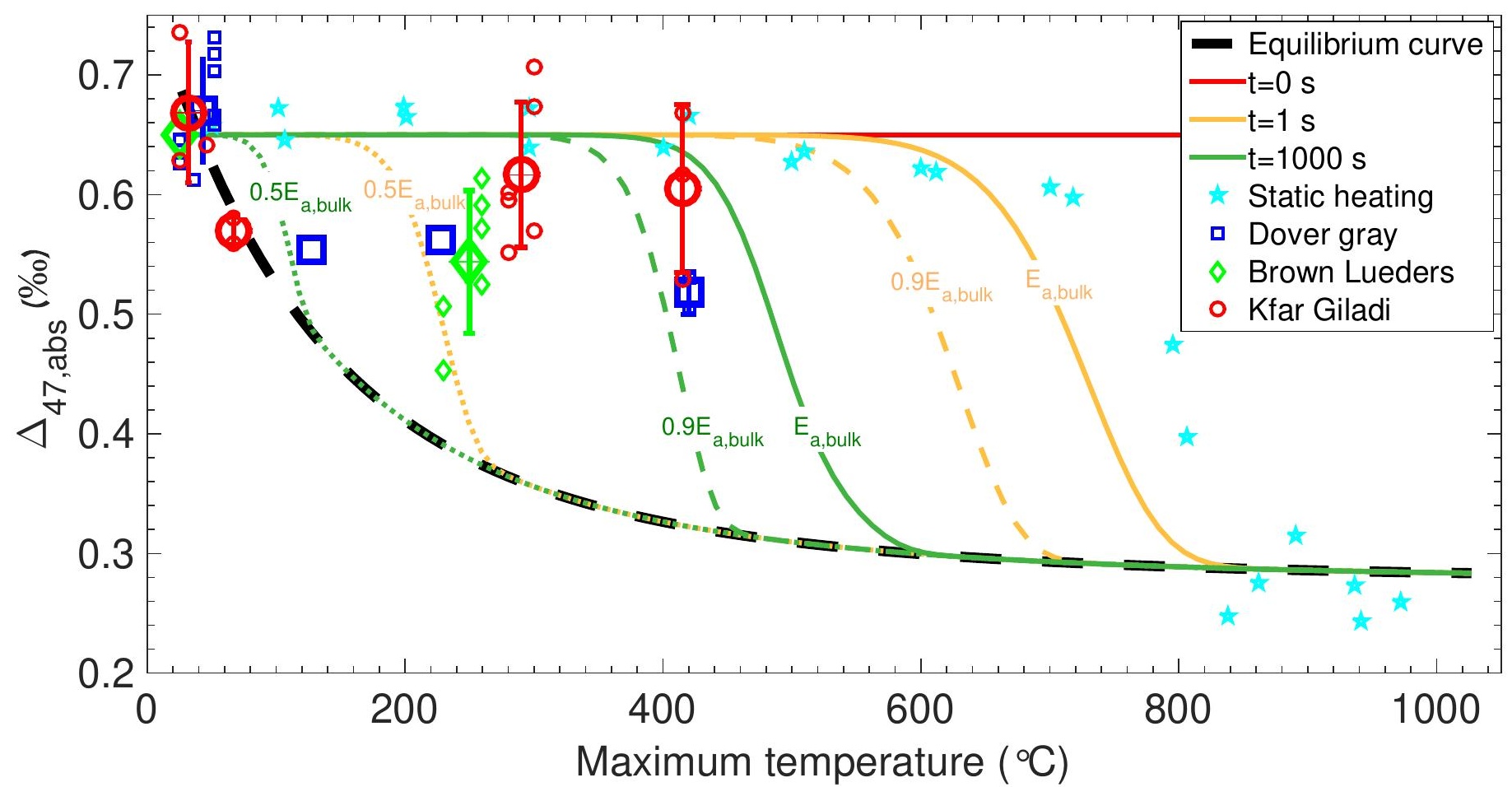


Table 1. Experimental conditions of static heating.

\begin{tabular}{|c|c|c|c|c|c|c|}
\hline Series & Sample & $\begin{array}{l}\text { Weight }^{\text {a }} \\
(\mathrm{mg})\end{array}$ & $\begin{array}{l}\mathrm{T}_{\max }{ }^{\mathrm{b}} \\
\left({ }^{\circ} \mathrm{C}\right)\end{array}$ & $\begin{array}{l}\text { Heating time }^{c} \\
\text { (s) }\end{array}$ & Time at $T_{\max }{ }^{d}$ & Cooling method $^{e}$ \\
\hline 1 & D101-D107 & $100-210$ & $800-1000$ & $25-78$ & $\sim 30 \mathrm{~s}$ & $\begin{array}{l}\text { Quenching in air, } 10 \mathrm{~min} \\
\text { Model cooling } \sim 30 \mathrm{~min}\end{array}$ \\
\hline 2 & D201-D208 & 50 & 100:100:800 & $2-26$ & $<1 \mathrm{~s}$ & Quenching in $\mathrm{LN}_{2},<5 \mathrm{~s}$ \\
\hline 3 & D301-D305 & 50 & $25,200: 200: 800$ & $10-100$ & $72 \mathrm{hr}$ & Quenching in $\mathrm{LN}_{2},<5 \mathrm{~s}$ \\
\hline 4 & D401-D408 & 50 & $100: 100: 800$ & $4-25$ & $<1 \mathrm{~s}$ & Model cooling 5-40 s \\
\hline
\end{tabular}

${ }^{\mathrm{a}}$ Powder weight before heating the sample.

${ }^{b}$ The maximum temperatures recorded by a thermocouple attached to the gold capsule. 100:100:800 indicates that each of the sample was heated to a different target $T_{\max }$ between $100{ }^{\circ} \mathrm{C}$ and $800{ }^{\circ} \mathrm{C}$ in temperature spacing of $100{ }^{\circ} \mathrm{C}$.

${ }^{c}$ Time required to reach $\mathrm{T}_{\max }$ from the initial (room) temperature.

${ }^{\mathrm{d}}$ The time duration that the sample was held at $\mathrm{T}_{\max }$. For series 2 and 4 this time is $<1 \mathrm{~s}$ as the sample was cooled immediately upon reaching $\mathrm{T}_{\max }$.

${ }^{\mathrm{e}}$ The time required to cool below $200{ }^{\circ} \mathrm{C}$ is given following the cooling method. The model cooling paths are different for series 1 and 4 , since a portion of the model parameters differ between the two calculations (see supplementary material for greater information). $\mathrm{LN}_{2}$ denotes liquid nitrogen. 